\title{
Contextualisation of the complexity in the selection of developing country outsourcees by developed country outsourcers
}

\section{Abstract}

Outsourcing research has recognised that selecting the right offshore supplier (outsourcee) in low-cost distant developing countries is complex, but central to outsourcing success. More specifically, the combination of outsourcee contextual internal factors (e.g. capabilities) with outsourced-to country contextual external factors (e.g. political, legal, economic, sociocultural) as two fundamental and inter-connected decisions firms make when outsourcing remains an underexplored research gap. Therefore, through a rigorous three-tier qualitative approach we, firstly, develop a contextual Environmental Separation Index (ESI) decision tool to help outsourcing firms in making more informed decisions when selecting outsourcees and outsourcing locations. Secondly, we operationalise the ESI as intuitive and easy to use decision tool, yet with a provision to deliver a truly context proof outsourcee selection decision. Thirdly, we adopt a complexity theory lens to explain that narrowing the contextual outsourcer-outsourcee gap facilitates a mind-set shift in outsourcing relationships from hierarchies to networks and from controlling to empowering developing country outsourcees. We show from a complexity theory perspective how contextual separation gaps between developed country outsourcers and developing country outsourcees can be an effective way to grasp the evolutionary path of outsourcing relationships.

Keywords: Outsourcing Decisions, Outsourcing Relationships, Supplier Selection, Supply Chains, Complexity Theory 


\section{Introduction}

In today's difficult economic climate, Identifying a qualified and eligible manufacturing partner has become more essential for reducing such costs and the evaluation and selection of potential outsourcees have become an important component of Supply Chain Management (SCM). Selecting a company to outsource to is not the same as choosing a regular supplier who provides raw materials or equipment. Outsourcing refers to the act of subcontracting some or all of a manufacturing process to an external partner and this implies embarking on a potentially longer term and uncertain relationship. Thus, it becomes vital to enlist the right outsourcing partners to create a competitive supply chain network (Dolgui and Proth 2013, Wiengarten, Pagell, and Fynes 2013).

Outsourcing has often been linked to a set of anticipated benefits including improved financial and operational performance and enhanced business focus and flexibility (Lockamy and McCormack 2010, Dekkers 2011, Dolgui and Proth 2013). However, recent research suggests that outsourcing firms are struggling to achieve the sought benefits from their outsourcing strategies (Handley and Benton 2013, Westphal and Sohal 2013, Bals, Kirchoff, and Foerstl 2016). The reasons why outsourcing firms are falling short of realising desired benefits from outsourcing includes: poor selection of outsourcees and locations (Pawar and Rogers 2013), improper management of outsourcing relationships (Yang et al. 2016), underestimating the resources needed to manage outsourcing relationships (Handley and Benton 2013) and lack in understanding of the long term impacts that outsourcee's capabilities have on the outsourcing firm's performance (Leng, Jiang, and Ding 2014, ScherrerRathje, Deflorin, and Anand 2014, Uluskan, Joines, and Godfrey 2016). Moreover, the task of evaluating and selecting an outsourcee becomes ever more complex when selecting suppliers 
in developing countries due to the added risks and uncertainties from disparate institutional and cultural systems (Huq and Stevenson 2018).

The outsourcing literature has studied extensively the internal factors considered while conducting outsourcee assessment and selection (Wadhwa and Ravindran 2007, Lockamy and McCormack 2010). A plethora of methods have been used. For example, outsourcing studies have developed frameworks for outsourcee selection applying traditional analytic hierarchy process (AHP) approach (Emrouznejad and Marra 2017), cost benefit AHPSort (Ishizaka and Lopez 2018), fuzzy set theory (Ordoobadi 2009, Kaur, Singh, and Majumdar 2018), group analytic hierarchy process ordering (GAHPO) (Ishizaka and Labib 2011), an integrated combination of both AHP and fuzzy set theory (Chen and Hung 2010, Che and Chiang 2012), a stochastic mixed integer programming approach (Dupont et al. 2018),a lean thinking outsourcee evaluation approach (Aamer 2018), and clustering procedures based on artificial neural network (ANN) (Medhi and Mondal 2016). Other studies have expanded beyond outsourcees' attributes and considered factors in the external environments including holistic cost of offshore manufacturing outsourcing to developing countries (Pawar and Rogers 2013), the state of "rule of law" in developing countries (Wiengarten, Pagell, and Fynes 2013) and the impact of national culture on governance effectiveness in outsourcing location decisions (Handley and Benton 2013, Handley and Angst 2015). The outsourcing research on external factors examined cultures and language (Schoenherr 2010), business environment friendliness and infrastructure (Kedia and Mukherjee 2009, Lewin, Massani, and Peeters 2009, Jensen and Pedersen 2011) are important influences of outsourcing success. 
While most of the supplier selection and outsourcing/offshore outsourcing decision models use multiple criterion decision making (MCDM) methodology to rate alternative suppliers based on internal performance specific criteria, they often require substantial efforts in accessing outsourcees' internal performance data and deriving scores to execute the chosen selection model (Chen and Chen 2006, Wadhwa and Ravindran 2007). In addition, despite addressing a wide set of external environment factors and their potential impact on firms'- post-outsourcing operational and financial performance, most of outsourcing location research studies focused only on single or major external factors. Moreover, the relationship between the two sets of outsourcees' internal factors and developing countries external factors remains unexplored. Therefore, combining outsourcee contextual internal factors with location contextual external factors as two fundamental and inter-connected decisions firms make when outsourcing in developing countries has been identified as a research gap (Hatonen and Eriksson 2009, Westphal and Sohal 2013). In this study, we provide a contextualisation approach that accounts for a range of key internal and external environmental factors associated with outsourcing relationships between developed country outsourcers and developing country outsourcees. We specifically aim to address the above outlined research gaps due to limitations in outsouree and location decision models by assessing how the contextual gap between outsourcers and outsourcees impacts their relationship type and evolution. We argue that it is important to understand what internal and external contextual factors should be considered by outsourcing firms when preparing for offshore outsourcing and how outsourcee and location contexts can influence outsourcer-outsourcee relationships. Thus, the purpose of this research is to shed light on this issue and provide insights and examples into current practices 
of European based manufacturing firms with active outsourcing relationships with developing country outsourcees.

Against this backdrop, we ask the following two inter-related research questions:

$R Q$ - 1: What are the contextual internal and external environmental factors developed country outsourcing firms should consider while sourcing from developing country outsourcees?

$R Q$ - 2: How does the difference in these factors influence the type of relationship they should have with their developing country outsourcees?

The study develops a contextualisation index - Environmental Separation Index (Buttol et al.) - as an outsourcing decision tool which incorporates key internal and external environmental factors in one decision tool. This combination highlights to decision makers in outsourcing firms the complex interactions between internal and external environments through the application of an easy to use decision tool, yet with a provision to deliver a truly context proof outsourcee selection decision.

We focus on manufacturing outsourcing relationships from developed European countries to India. According to European trade statistics, India was the $9^{\text {th }}$ largest exporting country to Europe in 2016, with a total of $€ 39$ billion accounting to $2.3 \%$ of the total European imports in 2016 (Eurostat 2016). In addition, Europe is India's number one trade partner, accounting to $13.5 \%$ of India's overall trade with the world in 2015-16 (European Commission 2016).

The study makes three novel contributions to the field. First, we design and introduce the contextual Environmental Separation Index (Buttol et al.) to help outsourcing firms in making more informed decisions when selecting outsourcees and outsourcing locations. The 
ESI is an intuitive and consistent indicator assessing contextual factors of potential outsourcee and outsourcing locations. The ESI emphasises that outsourcing relationships and success are often context dependent, therefore as a contextualisation tool, the ESI complement other outsourcee quantitative selection models by capturing subjective issues in relation with the evolution of outsourcees' firm performance, government policies and infrastructure development in developing countries. Second, we operationalise the ESI, utilising a benchmark assessment of the differences between the internal and external operations environments of an outsourcer and a potential outsourcee. Third, we adopt a complexity theory lens to explain that narrowing the contextual outsourcer-outsourcee gap facilitates a mind-set shift in outsourcing relationships from hierarchies to networks and from controlling to empowering. Accordingly, outsourcing relationships should not be just about assigning tasks and monitoring performance, but to empower and to nurture various supply chain actors.

\section{Literature Review}

\subsection{Outsourcee selection models}

Outsourcing arrangements are versions of buyer-supplier relationships. They are differentiated from standard buyer-supplier relationships by two main characteristics: (1) the transfer of operations from the outsourcer to the outsourcee (Dekkers 2011); and (2) the continuation of supply of the outsourced products or services at reduced cost, improved quality, shorter lead time and minimum disruption to customers (Goffin, Lemke, and Szwejczewski 2006, Bals, Kirchoff, and Foerstl 2016). Therefore, the effective selection and management of outsourcees is crucial for the outsourcing firm performance and its ability to 
achieve and sustain competitive advantage from the outsourcing strategy (Medhi and Mondal 2016).

Given the pivotal importance of building and developing highly cooperative outsourcing relationships for outsourcing success, previous research investigated factors underpinning successful selection of outsourcing partners. For example, Chen and Chen (2006) applied process incapability index to develop a supplier evaluation model to assess potential suppliers' product quality performance as the main selection criteria. Sucky (2007) developed a dynamic and generic vendor selection model suitable for strategic supplier selection. To incorporate a more subjective supplier selection approach, Ordoobadi (2009) applied fuzzy set theory to capture decision maker's preferences as expressed in linguistic terms or fuzzy logic. Similarly, Chen and Hung (2010) applied an integrated approach of fuzzy logic and AHP to develop an outsourcee evaluation and selection model to select outsourcing manufacturing partners based on multiple performance criterions (e.g. financial, quality, product, service). In another study Ishizaka and Labib (2011) developed the group analytic hierarchy process ordering (GAHPO) method as an improved AHP process that can be easily applied to strategic supplier selection problems. The new GAHPO method is adapted for group decisions with many stakeholders through assigning different weights to different decision-makers of the group, hence it is suitable for outsourcee selection decisions where more than one decision maker is usually involved (e.g. quality manager, supply chain manager , finance manager)(Ishizaka and Labib 2011).Using another AHP process, Che and Chiang (2012) applied an integrated approach of genetic algorithm and AHP to construct a collaborative supplier selection model optimising cycle time estimation procedure with production and distribution plans. 
The most recent production studies on supplier and outsourcing decision models contributed to this line of research. For example Medhi and Mondal (2016) proposed a clustering procedure based on artificial neural network (ANN) using a non-expert decision making approach that evaluates different suppliers based on information about their past performance, collected from indirect sources (e.g. previous employees, government agencies, competitors and other customers). Furthermore, in a recent study Arampantzi, Minis, and Dikas (2018) proposed a comprehensive model for supply chain network (SCN) design in global manufacturing. The authors argued that in order for global manufacturers to minimise investment and operational supply chain costs, they should incorporate allimportant characteristics of their multiple suppliers including procurement, production, inventory, warehousing, and transportation over the SCN design horizon (Arampantzi, Minis, and Dikas 2018). Ishizaka and Lopez (2018) adapted Cost-Benefit AHPSort to facilitate performance evaluation of offshore providers. Their method used multiple cost and benefit criteria to provide benchmarking of provider performance in the outsourced process relevant to the same provider previous period performance as well as in comparison with other providers performance (Ishizaka and Lopez 2018). Kaur, Singh, and Majumdar (2018) presented a joint model for optimising decisions of outsourcing and offshoring in a manufacturing supply chain. The proposed model involves selection of suppliers for different factories of the firm considering both qualitative and quantitative parameters (Kaur, Singh, and Majumdar 2018). Dupont et al. (2018) purposed to use a stochastic mixed integer programming approach to build a decision-support for supplier selection under the risk of delivery failures. Finally, Aamer (2018) applied an extended supplier evaluation method by considering supplier production/operations processes. His study used the lean 
value stream concept to identify operational-level criteria and their impact on supplier performance (Aamer 2018).

While most of the supplier selection models, including the ones we mentioned here, use a multiple criterion decision making (MCDM) methodology to rate alternative suppliers based on performance specific criteria including price, quality, lead-time, delivery reliability, information sharing, corporate culture alignment and technical capabilities, they often involve extensive efforts and a comparatively complex computation (Chen and Chen 2006, Wadhwa and Ravindran 2007, Kaur, Singh, and Majumdar 2018). In addition, these models have limited applicability as holistic and higher management outsourcing decision tools due to their limited perspective to only the supplier selection phase (Westphal and Sohal 2013). Thus it becomes important to also captrure the subjective internal factors, which complements quantitative outsourcee selection models.

Additionally, outsourcees are embedded in their institutional and national cultural environments, hence their operating practices are unavoidably influenced by the contextual factors of these environments (Lahiri and Kedia 2011). Several studies have examined the role of the external environment contextual factors in the selection of outsourcees. For example Kedia and Mukherjee (2009) argued that by joining the World Trade Organisation (WTO) some developing countries such as India and China have become more attractive for offshore outsourcing activities given reduced tariff levels and friendly foreign investment environments. In another study Jensen and Pedersen (2011) investigated the contexts of outsourcing locations (e.g. cost, human capital, business environment and interaction distance), arguing that outsourcing firms usually choose outsourcing locations that create the 
best fit between the nature of the outsourced task and the advantages offered by alternative locations.

Other studies devoted attention to studying specific factors in external environments. For example Wiengarten, Pagell, and Fynes (2013) hypothesised that countries' rule of law is a strong contextual determinant of outsourcing location decisions since it acts as a proxy of legal and regulatory system risk level. Moreover, Handley and Benton (2013) and Handley and Angst (2015) operationalised Hofstede's five cultural dimensions (uncertainty avoidance, individualism versus collectivism, power distance, masculinity versus femininity, and longterm versus short-term orientation) to study the impact of national culture on governance effectiveness in outsourcing location decisions. In similar vein, Caniato et al. (2015) concluded that outsourcing location drivers such as low cost, resource availability, cultural proximity, and local network can have significant impact on the outsourcing strategic and operational performance. Despite addressing a wide set of external environment factors and their potential impact on the outsourcing firm operational and financial performance post outsourcing, most of these studies focused only on single or major external factors.

Our proposed ESI tool incorporates all key external environment factors including government, national culture, infrastructure and national human resources in one decision tool. In addition, the ESI tool uses the two sets of key internal outsourcee and external location factors within the same outsourcing decision tool. The underlying process of building and applying the ESI tool recognises the complex task of finding and choosing the right manufacturing supplier in developing countries and therefore attempts to capture this complexity through the contextualisation of all key internal (outsourcee) and external (location) factors. 


\subsection{Contextual Internal Environmental Factors}

Cost, quality and reliability (see Table 1), have been popularly recognised in the outsourcing literature as key performance indicators (KPIs) of potential outsourcees' abilities to fulfil their supply obligations and satisfy the operational efficiency goals for buyers' outsourcing strategies (Leng, Jiang, and Ding 2014, Medhi and Mondal 2016). Additionally, due to their quantitative dimension, cost, quality and reliability have been extensively used to measure outsourcing success and monitor outsourcees' performance (Uluskan, Joines, and Godfrey 2016, Kenyon, Meixell, and Westfall 2016). However, SCM scholars are increasingly calling for the application of holistic and integrative models for defining cost, quality and reliability constructs to capture their qualitative, hidden and difficult to measure attributes which are proven to be very crucial for the outsourcing success (Pawar and Rogers 2013, Yang et al. 2016).

[Insert Table1]

The second set of contextual internal factors include: human resources (e.g. current labour skills level), internal culture (e.g. outsourcee's organisational values) and outsourcee integration (e.g. IT alignment) (see Table 1). It has been found that alignment of these factors leads to a higher level of inter-firm collaboration and partnering with a particular outsourcee (Pawar and Rogers 2013, Handley and Angst 2015, Kenyon, Meixell, and Westfall 2016). The human resources factor refers to the outsourcer evaluation of the outsourcee's tangible human assets prior to an outsourcing decision is made (Pawar and Rogers 2013). The evaluation process should address not only outsourcee human resources availability and skill levels to perform the outsourcing tasks but also the outsourcee's committed human resources to meet the outsourcing project specific needs as well as the human resources 
management capability of outsourcee (Goffin, Lemke, and Szwejczewski 2006, Plugge, Borman, and Janssen 2016). Therefore, the outsourcing research is increasingly linking cooperative outsourcing relationships with close attention to human resources management (Yang et al. 2016).

The internal culture factor in inter-firm relationships context refers to organisational similarities and dissimilarities between outsourcing partners, including management style, work place norms and values (Gulati and Sytch 2008, Paulraj, Lado, and Chen 2008). Accordingly, differences between outsourcing partners organisational styles, norms and beliefs can be detrimental to outsourcing relationships (Schoenherr, Narayanan, and Narasimhan 2015). Therefore, it is crucial that outsourcing partners establish a clear understanding of each other's internal culture earlier in the outsourcing relationship, as such understanding assist in building a trusting working environment between partners (Schoenherr, Narayanan, and Narasimhan 2015). Additionally, mutual goals and shared norms and values between outsourcing partners are known to generate trust and foster cooperative relationships (Handley and Angst 2015).

Finally, outsourcee integration, which refers to the level of outsourcing partners understanding of each other's internal process, is identified as key characteristic of successful outsourcing relationships (Westphal and Sohal 2013, Schoenherr, Narayanan, and Narasimhan 2015). Furthermore, recent outsourcing research concluded that outsourcee integration facilitated through information technology (IT) alignment and electronic data exchange, increases outsourcing success as it fosters trust formation, and reduces control and coordination costs (Kenyon, Meixell, and Westfall 2016). 


\subsection{Contextual External Environmental Factors}

Outsourcing relationships and performance are equally influenced by contextual external environmental factors. We identify government policy, national human resources, infrastructure and transport and national culture as key contextual external environmental factors (see Table 1). The outsourcing research widely demonstrated through comparative studies for different countries that government policies such as free trade policies, foreign investment regulations and the strength of legal system are strong indicators of how attractive or risky a country is as an outsourcing destination (Wiengarten, Pagell, and Fynes 2013, Bals, Kirchoff, and Foerstl 2016). Additionally, availability of highly skilled and educated human resources and transport and communication infrastructures are proven to be among strong determinants of manufacturing outsourcing location decisions (Kedia and Mukherjee 2009, Lewin, Massani, and Peeters 2009, Huq, Pawar, and Rogers 2016). Lastly, the outsourcing research exhibits that divergence of national cultures poses major challenges to the outsourcing performance through low familiarity and high outsourcees behavioural uncertainty (Tjader, Shang, and Vargas 2010, Handley and Angst 2015).

\subsection{Differences in contextual factors affecting outsourcing relationships: A Complexity Theory Perspective}

Carter, Rogers, and Choi (2015) have called for research into the application of complexity theory principles in the conceptualisation, understanding and management of supply chains. This includes the evolution of supply chains, in particular exploring why some supply chains grow, and why other supply chains expire. In this study we extend this body of work and conceptualise developed country outsourcer-developing country outsourcee supply chain relationships as complex adaptive systems (CAS) (Pathak et al. 2007, Day 2014, Carter, Rogers, and Choi 2015). Our goal from this approach is to study the impact of the outsourcer- 
outsourcee contextual separation gap on the type of outsourcing relationship (RQ2), using the complexity theory lens.

Viewing outsourcing relationships as CAS elevates outsourcee and location selection decisions from an individual outsourcer decision affecting a dyadic level only to a supply chain network level (Choi, Dooley, and Rungtusanatham 2001). CAS has been defined as a system of interconnected autonomous entities (e.g. outsourcers and outsourcees) that follow certain schema (values, norms and beliefs) and emerges overtime through adaptation and selforganising (emergence of new patterns and structures, e.g. alliance dynamics) without a single entity (e.g. focal firm) control (Pathak et al. 2007, Choi, Dooley, and Rungtusanatham 2001). Therefore, a CAS consists of the following elements: (1) organisational entities (2) an internal structure of interconnectedness between entities (chains of interrelationships between entities in a CAS), (3) an external environment (e.g. institutional and national culture systems) and (4) self-organising and emergent system performance (Pathak et al. 2007).

The central premise of CAS is that complexity is defined by relationships and interactions within entities, between entities and between entities and their surrounding external environments rather than by the attributes of individual entities (Manson 2001). Thus outsourcer-outsourcee relationships can be conceptualised as CAS that includes various suppliers from physical (product) and support supply chains of both entities (Carter, Rogers, and Choi 2015), customers networks of both entities, and the institutional and national culture environment of both entities. Consequently, understanding how CAS changes and evolves over time as a result of this vast scope of relationships and interactions is not a straightforward systemic process (Choi, Dooley, and Rungtusanatham 2001). Change in a CAS such as an outsourcer-outsourcee relationship, is continuous and characterised with 
dynamism and therefore is difficult to predict or control. However, through co-evolution and adaptability, entities in a CAS develop emergent patterns of behavior to deal with changes and improve their fitness (goodness) of performance according to a typical criteria (e.g. relationship type) (Choi, Dooley, and Rungtusanatham 2001). Therefore, an outsourcer decision to adopt an outsourcing strategy alters flows of material, information and services of the outsourced task(s), adds the entities of the selected outsourcee suppliers and customers' networks, as well as its external environment (i.e. government, human resources, infrastructure and national culture). As a result of this complex web of relationships and interactions in the outsourcing relationship, new control and coordination patterns emerge and impact the type of outsourcing relationships and outsourcing performance.

Against this backdrop, we argue that the conceptualisation of the outsourcing relationship as a CAS, along with the application of the proposed ESI decision tool, will help us understand how differences in internal and external contextual factors can influence the type of relationship developed country outsourcers should have with developing country outsourcees.

\section{Methodology}

We adopted a three tier qualitative approach for our investigation of the contextual factors of outsourcing. This included an extensive literature review (Section 2), an expert workshop (Section 3.1) and a multiple case study of four European based outsourcing firms with existing manufacturing outsourcing activities in India (Section 3.2). Although the study was largely exploratory in nature, it had the following specific objectives:

- Identify a list of key contextual factors from the literature. 
- Verify the factors by utilising an expert workshop and a number of case studies to develop a deeper understanding of the contextual internal and external environmental factors and their influence on outsourcing relationships types.

- Develop the proposed Environmental Separation Index (Buttol et al.) as a contextualisation decision tool through operationalisation of identified key contextual factors from the case studies.

- Use the same case studies as an illustrative example to validate the assumptions and application of the proposed ESI tool.

- Apply complexity theory lens to explain outsourcing relationship types as a result of low/medium/high outsourcer-outsourcee contextual separation gap at each key factor level.

\subsection{Expert Workshop - India}

To verify the ESI contextual factors identified during the literature, we first utilised an expert workshop to capture research and practice insights about contextual factors in offshore outsourcing through open-ended questions. A panel of 39 expert academics and industry practitioners participated in a workshop during an International Logistics conference hosted in Bangalore, India. The location of the conference ensured a strong local representation, in addition to travelling delegates from Europe and the rest of the World. The academics group included 18 participants, 10 from India and 8 from Europe. Majority of our academics were professors from fields of production, information systems, operations and supply chain management with vast experience of research and publications in their disciplines. The practitioners group included 21 participants from India, Europe and around the world. Our 
industry experts represented several industry sectors and global organisations including; 1 ) Multinational manufacturing enterprises of food, leather and shoes, luxury goods, mining and constructions equipment, personal computers and precision machinery and electronics, 2) Global corporations of information system software and applications, and 3) Global logistics services providers. All practitioner participants held top senior management positions in their organisations. The workshop interactions and synergies between the accumulated knowledge held in the group of expert participants brought out various insights about the context of transferability of manufacturing supply chain activities from Europe to India.

The workshop was structured around three tasks:

Task One - participants were asked to identify one external (macro) level issue to be considered in the transfer of operations from Europe to India, along with three internal (micro) level issues. Subsequently, participants collectively reviewed and clustered the issues to identify themes.

Task Two - in small groups, the participants discussed the impact of these issues and proposed means of overcoming them.

Task Three - participants provided examples of successful and unsuccessful outsourcing experiences, to illustrate the impact of contextual factors and add substance to the identified issues.

\subsection{Multiple Case studies- European Outsourcers}

To further validate the contextual factors of the proposed ESI tool, a multiple case study research was conducted to capture the perspectives of European outsourcing firms about their outsourcing experiences in India. The four cases included three original equipment 
manufacturers (OEMs) from UK and one from Sweden. All selected companies were large firms with extensive global presence and relatively long history of outsourcing to India (more than 10 years). The case companies also, have outsourcing experiences in other developed and developing countries as well. The use of purposive sampling strategy was chosen specifically to provide insightful, comprehensive and information rich account of the developed ESI tool (Robinson 2014). We reduced variation by selecting only European manufacturing firms having outsourcing relationships in India, which enabled us to do crosscomparison, thus ensuring validity.

Here multiple case studies are considered an appropriate method of inductive qualitative study as it allows direct observations and provides first-hand understanding of real-life circumstances (Yin 2009). Moreover, it is suitable for answering "what" and "how" questions and enables in-depth analysis (Saunders, Lewis, and Thornhill 2009, Eisenhardt 1989) and inductive theory building (Yin 2009). Through our case study research, we managed to unpack the complexity of the outsourcing firm task in evaluating and selecting developing country outsourcees.

We conducted nine (9) face to face detailed semi-structured interviews with relevant managers (see Table 2), to discuss the issues related to key contextual factors in their outsourcing decisions and relationships in India. Detailed notes were taken during each interview. Interviews were followed by factory tours, where interviewers were allowed to record further notes supplementing the collected data from the interviews (Miles and Huberman 1994). As a result, the triangulation logic could be achieved by using multiple sources of evidence (Yin 2009). Data collection ended when theoretical saturation was reached i.e. no new information was produced from subsequent cases (Eisenhardt 1989). 
We developed theory from the data through a theory building multiple case study approach (Eisenhardt, Graebner, and Sonenshein 2016). We analysed the firms individually to identify patterns in each case, before conducting cross-case analysis. We searched for the similarities and differences across the data by constant comparison, which helped strengthen the research findings and ensure validity (Yin 2009). Therefore, using a structured approach to data collection and analysis enabled us to enhance the analytical rigour of our research (Lincoln and Guba 1985). Through this multipronged qualitative approach, we were able to operationalise our proposed ESI outsourcing decision tool.

Lastly, we use complexity theory to suggest explanations for our empirical findings from this inductive qualitative research. The relevance of a theory can emerge after data has been collected, especially if it can make a powerful contribution in aiding understanding of the phenomenon (Zorzini et al. 2015). We contribute towards theory expansion by broadening the complexity theory perspective to a new empirical context and through our analysis offer substantive explanation, thereby enabling novel managerial implications to be derived (Ridder, Hoon, and McCandless Baluch 2014).

[Insert Table 2]

\section{Findings: Developing and Operationalising the Environmental Separation Index (Buttol} et al.)

First, the internal and external contextual factors' scores were determined using measures published in peer reviewed academic journals (see Table 3a), widely practiced key performance indicators (e.g. overall equipment efficiency and on time delivery) and global development proxies (e.g. World Bank's Ease of doing Business Index and Transparency 
International's Corruption Perception Index) - see Tables 3a and 3b. Next, the expert workshop confirmed cost, quality, reliability, human resources and outsourcee integration as key contextual internal factors, pointing out that all these factors are interconnected. The participants were in agreement that cost considerations in outsourcing must go beyond shortterm savings and include the impact of quality, human resources and supply chain uncertainties on the overall cost of outsourcing. Similarly, they were of the view that the outsourcee's human resources commitments to fulfil the outsourced tasks are crucial to achieve smooth transfer of operations and uninterrupted flow of products and information.

The participants in our expert workshop highlighted that a country's human resources' skill levels and availability of transport, energy and communication infrastructure are crucial location specific factors that often get neglected by developing country outsourcers. Furthermore, while expert participants discussed cultural differences as one of the contextual external environmental factor in offshore outsourcing, they proposed that government policy and availability of infrastructure play - by and large - a more dominant role than cultural distance in affecting outsourcing relationships and performance in the offshore context. Similarly, it was found that government policy and infrastructure factors are adequately represented in the European outsourcers' management agenda.

We constructed the ESI as a single estimate score summarising the identified key contextual internal and external environmental factors in outsourcing relationships (Foa and Tanner 2012), which in turn was validated through the case studies. However, a number of additional contextual factors (e.g. safe working conditions and green practices) emerged inductively through our case study analysis which was not identified in the first two stages (See Table 4). 
We categorise three levels of separation gaps as low/medium/high. Internal separation gaps are determined by comparing outsourcee score of each factor with the outsourcer target. External separation gaps are determined by comparing outsourcee's developing country scores with outsourcer's developed country scores. We assumed equal weights for all factors, since the goal of the ESI is to serve as intuitive yet informative and easy to estimate decision index (Khramov and Lee Ridings 2013). For simplicity purposes, we used equal weights for multiple items factors (Foa and Tanner 2012). Tables 3a and 3b illustrates the operationalisation procedure to estimate the ESI internal and external separation gap respectively.

[Insert Tables 3a and 3b]

\subsection{Outsourcer-Outsourcee Internal Contextual Factors' Separation Gap}

The outsourcer-outsourcee separation gap for internal factors is rated as "low=1" if the outsourcee meets or exceeds the target of the assessment criterion, "medium $=2$ " if it is $33 \%$ or less away from the target or "high=3" if it is more than $67 \%$ away from target. The quality management system certification (e.g. ISO 9000) under quality factor and the three items measuring integration measured as "low=1" or "high=3" since there isn't an intermediate scenario for these factors given their assessment nature.

Cost: The Automaker Company established explicit cost saving targets for its developing country outsourcees ranging from $20-50 \%$ in comparison with production costs in-house or in nearshore locations. The three other cases reported that achieving cost savings was the primary drive of their outsourcing strategies in India. Accordingly, we measure cost saving separation gap by comparing cost before outsourcing with outsourcee's cost. 
Quality: The Heavy Trucks Company insisted that outsourcees must hold an international quality certification (e.g. ISO 9000). Additionally, the company followed a stringent vendor quality performance rating based on very tight quality targets (e.g. 80 defects per million parts). The Supplier Development Executive of the Heavy Trucks Company stated that: "...quality is of utmost importance to us, we therefore make considerable investment in developing capability in our Indian supply chain...". Moreover, the Automaker Company issued a handbook to each outsourcee with detailed quality requirements. While in both cases of the Valve Actuation and the Diesel Engines companies, a rigorous audit of outsourcees' quality took place before commencing the outsourcing relationship. The Diesel Engines Company insisted that Indian outsourcees must achieve the same quality performance of equivalent Western suppliers.

Consequently, we measure quality separation gap with two items: (1) outsourcee's quality management system certification e.g. ISO 9000 (Uluskan, Joines, and Godfrey 2016). (2) outsourcee's quality performance by comparing outsourcee's current customer rejection rate with outsourcer desired target of rejection rate (Ordoobadi 2009). Two out of our four cases insisted that outsourcees must hold an international quality certification (e.g. ISO 9000).

Reliability: All four cases applied a well-structured and standard pre-assessment process including review of potential outsourcees' historical track records, feedback from previous and current customers and physical assessment visits before commencing the outsourcing relationship. Additionally, our case study companies gave high attention to outsourcees' delivery performance through monitoring of on-time delivery scores. For example, the Heavy Trucks Company instituted for outsourcees an on-time delivery target of $95 \%$ and the Diesel Engines Company required from each outsourcee to hold 4 weeks safety stock to ensure 
timely delivery. Moreover, all fours cases conducted regular audits of outsourcees as a mechanism to evaluate and improve outsourcees' reliability performance.

Therefore, to measure the reliability separation gap, we use three measures: (1) outsourcee's on time delivery performance, (2) outsourcee's order cycle time performance (Tan 2007), and (3) outsourcee's overall equipment efficiency (Kenyon, Meixell, and Westfall 2016).

Human Resources: The case companies addressed the human resources factor at the outsourcee level as part of the pre-outsourcing capability assessment procedure with focus on its ability to access the required volume and skill levels of human resources and the time required to recruit and train skilled personnel to perform the outsourcing tasks. For example, the Automaker Company selected outsourcees who have access to design and development skilled employees. Accordingly, to operationalise human resources separation gap, we use two human resources management indicators (1) outsourcee's employee turnover, and (2) outsourcee's employee tenure (Pawar and Rogers 2013, Kenyon, Meixell, and Westfall 2016), both measured in comparison with the outsourcer set targets.

Internal Culture: All four cases focused on working with less number of outsourcees given the resource and the managerial attention required in transferring operations through outsourcing. Additionally, they preferred to partner with outsourcees, who exhibited top management commitment, long term orientation and willingness to invest financially and socially in building strategic relationships rather than transactional buyer-supplier relationships. One of the interviewees from the Heavy Trucks Company noted that, 'whilst, the outsourcer might make a decision as to what element of the value chain the company wants to outsource; but quintessentially the outsourcee thereof might want to move up the 
value chain transaction. Therefore, one should attempt to better understand outsourcee perspective in order to develop a long term sustainable relationship...'.

Accordingly, For internal culture separation gap, we rate the following three items using five point Likert scale ( 1 - strongly disagree to 5 strongly agree): (1) outsourcee's organisation long term orientation (Gulati and Sytch 2008), (2) outsourcee's centralisation of decision making process (Paulraj, Lado, and Chen 2008), and (3) outsourcee's bureaucracy (Paulraj, Lado, and Chen 2008).

Integration: The European outsourcers in our case studies stressed that potential and selected outsourcees must understand the requirements of the outsourced jobs and have documented production and quality procedures in place to make sure that they meet these requirements. For example, in the case of the Valve Actuation and the Heavy Trucks companies, specialised and complementary skills of potential outsourcees or their close proximity to large customer base guided the selection decision of these particular outsourcees and locations respectively. In addition, in the case of the Diesel Engines Company the use of common computerised planning software led to higher accuracy of material planning and ordering processes, ensuring better integration.

Therefore, to measure outsourcer-outsourcee integration separation gap we apply three items from Flynn, Hou, and Zhao (2010): (1) outsourcee's application of enterprise resource planning application (ERP) for data integration among internal functions (e.g. material requirements planning MRP), (2) outsourcee real-time inventory and logistics data availability, and (3) if the outsourcee has a computerised customer ordering system in place. 
Finally, our case study companies have paid special attention to social and environmental sustainability practices as part of their outsourcee selection process. Interviewees from the four cases stated that meeting minimum international safety requirements is a determining factor in outsourcee selection decisions. Moreover, the Automaker Company included a critical safety check list in their pre-assessment and reevaluation outsourcee audit visits. The Heavy Trucks Company selection process favoured outsourcees who were ISO14000 certified (international environmental management system certificate). Furthermore, the company issued to all existing and potential outsourcees an auditable black list and grey list of banned from use and phased out chemicals respectively. Table 4 illustrates the frequency of application of the ESI internal separation factors in our case study companies.

[Insert Table 4]

\subsection{Outsourcer-Outsourcee External Contextual Factors' Separation Gap}

The first three external factors (government policy, national human resources and infrastructure and transport) are measured using international proxies, where developed countries usually achieve positive scores and developing countries score negative. Additionally to measure the national culture separation gap, we use Hofstede's five dimensions: (1) power distance (e.g. UK 35, India 77), (2) individualism-collectivism (3) masculinity-Femininity (4) uncertainty avoidance, and (5) short/long-term orientation (Hofstede 1980, Hofstede and Minkov 2010).

To estimate the outsourcer-outsourcee separation gap for each external factor of the ESI tool we propose three ranges for each measure - A, B and C, which are assigned relative 
to developed country scores in the selected international indices and globally recognised development measures (See Table 3b). Thereafter, the outsourcer-outsourcee external separation gap is ranked "low $=1$ " in case both countries are located in the same range (e.g. A \& A), "medium=2" if the two countries are located in two consecutive ranges (e.g. A \& B), and "high=3" for otherwise (e.g. A \& C).

We now illustrate with an example the step by step procedure to calculate the external separation gap using the UK as the developed outsourcer country and India as the developing outsourcee country (See Table 5). For ease of access, we also provide the details of the measures and corresponding data source/link for each of the proxies of the factors in Table 5.

\section{[Insert Table 5]}

Government Policy: The case study companies recognised that countries' efforts in attracting foreign investments to enhance local industries and improve their technological and human talent competencies usually influence outsourcing location decisions. The Automaker, the Heavy Trucks and the Diesel Engines companies in our study were attracted to India in part due to the Indian government policy, which promoted for decades the auto and power parts industrial development. The Automaker Company stated that they were not satisfied with outsourcing experiences in Southeast Asia compared to India as suppliers were linked to state owned companies and this made it difficult to control and coordinate business with outsourcees. On a different government policy dimension, our case companies shared explicitly their concerns over weak intellectual property rights (IP) records in developing countries. For example, the Value Actuation Company stated that Outsourcing in China was perceived risky due weak intellectual property rights record. 
To estimate government policy outsourcer-outsourcee separation gap we used: (1) the outsourcee's country free trade policy measured in terms of membership in the World Trade Organisation (WTO). Both UK and India are both members of the WTO, therefore they fall in the same range "A=yes" and their ESI external separation gap for this factor is "1=low" (Table 5). (2) Ease of doing Business Index (Jayasuriya 2011) - 190 countries ranked from 1-190 with the world average score of 96 in 2017. Since developed countries usually score within the first $30 \%$ percentile for ease of doing business, we propose range A (1-64), range B (65-125) and range $C$ (126-190). As shown in Table 5, the ease of doing business index for the UK is 7 and for India is 100 , therefore the two countries fall in ranges A and B respectively, which leads to "2=Medium" ESI external separation gap for this factor.

(3) Rule of Law Index (Wiengarten, Pagell, and Fynes 2013), which ranges from -2.5 to 2.5, and 2.5 as best result (World Bank 2015). Since developed countries' rule of law scores are usually within the best $30 \%$ percentile of this scale, we propose range $A$ ( 0.85 to 2.5 ), range $B$ (less than 0.85 to -0.85 ) and range $C$ (less than -0.85 to -2.5 ). As shown in Table 5 , rule of law index for the UK is 1.8 and for India is 0 , therefore the two countries fall in ranges A and B respectively, which leads to "2=Medium" ESI external separation gap for this factor. (4) The Corruption (Freel and Robson) Perception Index (Pawar and Rogers 2013) ranges from 0 (corrupted) to $100 \%$ (free of corruption). Since developed countries corruption (Freel and Robson) scores are usually in the $30 \%$ most corruption free countries, we propose range $\mathrm{A}$ (67-100\%), range B (34-66\%) and range C (1-33\%) (Transparency International 2016). As shown in Table 5, the Corruption (Freel and Robson) Perception Index for the UK is $81 \%$ and for India is $40 \%$, therefore the two countries fall in ranges A and B respectively, which leads to "2=Medium" ESI external separation gap for this factor. 
National Human Resources: The Automaker and the Heavy Trucks companies told us that India was favoured as an outsourcing destination in comparison with other Asian destinations due to its well-built human resources' skills and competencies in the auto parts industries. For the Diesel Engines Company, manpower availability in India was a fundamental motive for choosing it as an outsourcing destination. Accordingly, to estimate national human resources separation gap, we used a World Bank Education Index, which measures the percentage of population with tertiary education for age group 25-34 years, ranging from 1$100 \%$ (OECD 2016). Since developed countries scores for this index are usually more than $50 \%$, we propose for range $A$ (more than $50 \%)$, range B (25-49\%) and range C (1-24\%). As shown in Table 5, tertiary education index for the UK is $52 \%$ and for India is $13.9 \%$, therefore the two countries fall in ranges $A$ and $C$ respectively, which leads to " $3=$ High" external separation gap for this factor.

Additionally, we used the world's average Productivity Index (PI) from the International Labour Organisation (ILO). The PI index estimates country labour productivity as Gross Domestic Product (GDP) in US\$ per number of population employed, with the world average of US\$35,084 (International Labour Organization 2017). We suggest the following three ranges for the $\mathrm{PI}$ index; $\mathrm{A}$ (more than the world average $\mathrm{PI}$ ) or $\mathrm{B}$ (equal to the world average $\mathrm{PI}$ ), and C (less than the world average $\mathrm{PI}$ ). As shown in Table 5, the UK $\mathrm{PI}$ is US\$ 79,331 and for India is US\$17,150, therefore the two countries fall in ranges $A$ and C respectively, which leads to "3=High" ESI external separation gap for this factor.

Infrastructure and Transport: For the Automaker, the Valve Actuation and the Heavy Trucks companies, regional location selection of their outsourcees in India was largely driven by ease of transportation, ports and logistics services proximity. For example, the Heavy 
Trucks Company selected outsourcees' locations within India based on availability of alternative routes to sea ports. Therefore, to estimate infrastructure and transport separation gap, we use three popular World Bank infrastructure development and enterprise indices: (1) rural access to all season's roads (0-100\% - higher percentage is better). Since developed countries scores are usually within the highest $15 \%$ percentile of this scale, we propose three ranges A (87-100\%), B (50-70\%) and C (5-49\%) (World Bank 2016). As shown in Table 5, the UK ccountry's rural access to all seasons roads is $(87-100 \%)$ and for India is $(50-70 \%)$, therefore the two countries fall in ranges A and B respectively, which leads to "2=Medium" ESI external separation gap for this factor.

(2) Enterprise percentage of losses of annual sales due to electrical outage. Since developed countries scores are usually $0 \%$ on this scale, we propose for range $A$ ( $0 \%$ sales losses), range $\mathrm{B}(0-1 \%)$ and range $\mathrm{C}$ (more than $1 \%$ sales losses) due to electrical outage (World Bank 2017). As shown in Table 5, the UK enterprise losses in sales due to Electrical Outage is $0 \%$ and for India is $2 \%$, therefore the two countries fall in ranges $A$ and $C$ respectively, which leads to "3=High" ESI external separation gap for this factor.

(3) Days to clear export container through customs. Since best scores for developed countries in this scale are between 0-1 days, we suggest three ranges $\mathrm{A}$ (0-1 day), B (2-3 days) and C (more than 5 days) (World Bank 2017). As shown in Table 5, the UK Days to Clear Export Container Through Customs is 2 days and for India is 5.8 days, therefore the two countries fall in ranges $B$ and $C$ respectively, which leads to "2=Medium" ESI external separation gap for this factor.

National Culture: Interviewees from four cases identified cultural differences between Europe and India as important contextual external factor. For example, the Director of 
Sourcing from the Diesel Engines Company stated that: “...there are huge disparities in Indian and European culture such as Indian suppliers never say, 'no', yet often fail to deliver to promises. Therefore, the role of my team is to carefully evaluate supplier capability and then set realist targets...". Moreover, the Heavy Trucks Company employed qualified professional Indians in managing outsourcees an effective mechanism to bridge cultural distance between Europe and India.

We propose for each of Hofstede's national culture dimensions three ranges A (033\%), B (34-66\%) and C (67-100\%). In Table 5 UK scores for power distance $35 \%$ and India scores $77 \%$, therefore the two countries fall in ranges $B$ and $C$ respectively, which leads to "2=Medium" ESI external separation gap for this national culture dimension. UK scores for individualism-collectivism $89 \%$ and for India is $48 \%$, therefore the two countries fall in ranges C and B respectively, which leads to "2=Medium" ESI external separation gap for this dimension. UK scores for masculinity-femininity $66 \%$ and India scores $56 \%$, therefore the two countries fall in range $B$, which leads to "1=Low" ESI external separation gap for this dimension. UK scores for uncertainty avoidance $35 \%$ and India scores $40 \%$, therefore the two countries fall in ranges B which leads to "1=Low" ESI external separation gap for this dimension. Both UK and India scores 51\% for short/long-term, therefore the two countries fall in range B which leads to "1=Low" ESI external separation gap for this dimension.

Finally, the overall ESI rank is estimated by calculating the average of the difference of all internal and external factors i.e. the separation gap. We propose the following range: $(0<$ Low $\leq 1),(1<$ Medium $\leq 2)$ and $(2<$ High $\leq 3)$. In our worked example, the external separation gap was 1.92 (See Table 5), which indicates that the difference in external contextual factors between UK and India is medium. Understandably, as no one case company was willing to 
share all information in regard to its internal contextual factor targets and related outsourcees' performance, we were not able to carry out the same exercise for the calculating the internal separation gap. However, we showed through our cross case analysis how these firms considered the internal factors and provided pertinent examples where possible (see Tables 3a and 4). This should facilitate outsourcers who have access or can gain access to internal measures and targets in calculating the internal separation gap.

\section{Discussion: Theorizing how differences in Internal and External Contextual Factors} influence Outsourcer- Outsourcee Relationship using the Complexity Theory Lens

We use the complexity theory lens to understand the phenomenon of how the differences in internal and external contextual factors influence the type of relationship developed country outsourcers should have with their developing country outsourcees. Since "complexity is characterised by contextuality" (Manson 2001, p408), we developed a contextualisation decision tool - the ESI, in order to capture this complexity. The ESI tool highlights for outsourcers the need to consider both the context in which their outsourcees operate and how they build and develop a relationship in the long run. By evaluating and examining the two levels of contextual environmental factors, outsourcers can decide the degree of their involvement in control and coordination of the outsourcing relationship. Furthermore, they can assess risks of external environments, monitor and mitigate these risks throughout the outsourcing relationship (Hansen, Mena, and Skipworth 2017, Zorzini et al. 2015). The ESI score can be beneficial since it starts from the same reference point to evaluate all potential outsourcees and locations. More importantly, the ESI score sets the outsourcer expectations of how might the selected outsourcee perform and determines chances of the outsourcing relationship evolution and success. 
We argue that the ESI separation level signals differentiated level of cooperation and therefore suggests different relationship types, where each has different capacity for achieving outsourcers' goals throughout the outsourcing engagement. The supply chain and outsourcing literature recognised that different types of relationships between outsourcers and outsourcees could be placed on a spectrum ranging from "out-tasking "to "partnership" (Beaumont and Sohal 2004), "tightly" or " loosely" controlled (Handley and Benton 2013), or "short term "to "long term" or "long term with no end" relationships (Kenyon, Meixell, and Westfall 2016). The task based outsourcing relationships are usually consistent with transaction cost economies (TCE) framework, where the outsourcer controls the outsourced tasks, specifies how they should be performed and applies formal and legal governance mechanisms in managing the relationship (Wiengarten, Pagell, and Fynes 2013, ScherrerRathje, Deflorin, and Anand 2014, Kenyon, Meixell, and Westfall 2016, Yang et al. 2016). In contrast, long term or partnership-like outsourcing relationships are characterised with higher levels of trust and commitment and hence allow the outsourcee greater degree of autonomy and control over its processes (Schoenherr, Narayanan, and Narasimhan 2015, Brahm and Tarzijan 2016). Additionally, recent outsourcing research concluded that long term outsourcing success is associated with developing close and long term outsourcing relationships fostered by mutual trust, effective communication and win-win mentality (Pawar and Rogers 2013, Medhi and Mondal 2016).

In line with this argument and based on our empirical exploration, we rank the overall outsourcer-outsourcee separation gap into three levels of separation - $(0<$ Low $\leq 1), \quad(1<$ Medium $\leq 2)$ and $(2<$ High $\leq 3)$. These ranges indicate that outsourcers may experience different types of outsourcing relationships with different outsourcees in developing 
countries given how far business environments in both contexts are distant. Based on the ESI internal and external separation ranking we label three types of outsourcing relationships (see Figure 1): (1) "master-servant" for overall high ESI scores (2<ESI $\leq 3)$ and, (2) "consultantclient" for overall medium ESI scores $(1<\mathrm{ESI} \leq 2)$, and (3) "peer to peer" for overall low ESI scores $(0<E S I \leq 1)$. A "master-servant" type indicates a tasking or transactional outsourcing relationship dominated by outsourcers' control. A "client -consultant" type refers to an outsourcing relationship that focuses on providing expertise and goods in an efficient manner. A "peer to peer" suggests a close and collaborative partnership type outsourcing relationship.

\section{[Insert Figure 1]}

Applying complexity theory lens, a high internal ESI indicates a lower level of outsourcer-outsourcee fitness and therefore motivates excessive control from the outsourcer (Choi, Dooley, and Rungtusanatham 2001). Here the outsourcer has low confidence in the outsourcee's capability to perform the outsourced tasks due to different practices and processes. Accordingly, the outsourcer uses detailed control and supervision or a" masterservant" relationship type. Conversely, with higher level of shared practices and processes, a low or medium internal ESI is achieved suggesting better outsourcer-outsourcee fitness. Therefore, a more collaborative outsourcing relationship type emerges as "client-consultant" when outsourcers for example reward outsourcees' improved on time delivery performance with extended future orders (Brahm and Tarzijan 2016). Moreover, a sustained collaborative or "peer to peer" outsourcing relationship is achieved when for example outsourcee reduces price as a result of cost savings from enhanced collaboration with the outsourcer (Liker and Choi 2004). Consistent with the features of CAS, a "peer to peer" outsourcing relationship has higher capacity to deal with change and is more dynamic compared to "master-servant" and 
"client-consultant" relationships. First, "peer to peer" relationships appreciate goal compatibility of outsourcing partners and therefore allow outsourcees to co-evolve and improve their fitness in the outsourcing relationship, while adapting to changes in their local networks and institutional environment (Manson 2001). Second, "peer to peer" relationships allow outsourcers to benefit from emergent behaviour of outsourcees as a more effective way of managing the outsourcing relationship (Choi, Dooley, and Rungtusanatham 2001). Third, increased outsourcees' autonomy in "peer to peer" relationships, can increase levels of outsourcee driven innovation in the outsourcing relationship (Choi, Dooley, and Rungtusanatham 2001), since sustained collaboration allow open knowledge flow and synergetic value creation under conditions of power balance and fair shares of risks and gains (Dyer and Singh 1998). Despite the advantages of "peer to peer" outsourcing relationships, not all outsourcers are necessarily aiming to achieve a "peer to peer" type in their outsourcing relationships. Nonetheless, "peer to peer" relationships are more resilient and efficient since they accommodate the complex reality of outsourcing relationship (Pathak et al. 2007).

The outsourcer-outsourcee relationship can be thought of as a CAS, which posits that it can unavoidably be affected by the numerous interactions within and between different teams and individuals at both ends of the outsourcing relationship, including the density and longevity of these interactions (Choi, Dooley, and Rungtusanatham 2001, Pathak et al. 2007). For example, there is likely to be a lack of trust and a misunderstanding of the different contexts in which the two sides operate (Schoenherr, Narayanan, and Narasimhan 2015). In time, however, the relationship evolves through repeated transactions and realised relational benefits (Dyer and Singh 1998, Handley and Angst 2015), which can cause the ESI to change from high to medium to low. Therefore, positive changes in ESI can be influenced by changes 
in the outsourcee contextual internal environmental factors such as improvements in cost and quality performance, increased alignment with the outsourcer's goals and higher degree of outsourcer-outsourcee integration.

Similarly, the outsourcer-outsourcee relationship can be impacted by interactions and dynamism among and within the outsourcee institutional environment (Choi, Dooley, and Rungtusanatham 2001, Pathak et al. 2007). Therefore, positive or negative shifts can occur in the outsourcee's country contextual external environmental factors causing the ESI to change and the relationship to experience growth in closeness or further separation. For example political risks such as government instability and civil war in some developing countries are arguably a common place of how macro shifts in external environments can impact outsourcing relationships (Hansen, Mena, and Skipworth 2017).

A mind-set shift from hierarchies to networks and from controlling to empowering can potentially narrow the separation gap in outsourcing relationships. Thus, outsourcing relationships should not be just about assigning tasks and monitoring performance, but to empower and to nurture supply chain actors. The Supplier Development Executive in the Heavy Trucks Company echoed that logic through encouraging their first tier suppliers in India to develop their upstream Indian suppliers and consequently building a larger pool of compliant first and second tier local suppliers. Likewise, the rise of the Mexican aerospace industrial clusters is another example of how the physical presence of a large aerospace OEM such as Rolls-Royce has led to the boom of Mexican aerospace industry through spontaneous development of many small and medium sized suppliers and sub-suppliers (Selko 2012). Consequently, the formation of these industrial clusters have fostered a growth in the number 
of aerospace supplier factories in Mexico from 150 in 2007 to more than 300 by end of 2016 (Sehl 2018).

Finally, drawing upon CAS's dynamism propositions, ESI outsourcer-outsourcee gaps can also experience negative shifts from low to medium to high and that negative change could ultimately lead to the failure or termination of the outsourcing relationship. For example, outsourcee and location decisions solely driven by cost savings can possibly lead to disappointing results in the medium to long term due to poor productivity, low skills or lack of infrastructure associated predominantly with low cost outsourcees and some low cost countries. In these scenarios, the ESI can experience negative shifts, increasing the gap between outsourcing expectations and actual results and causing the relationship to stagnate or retreat to a "master-servant" type or even terminate (Handley and Benton 2013, Bals, Kirchoff, and Foerstl 2016).

\section{Conclusions}

In this study we set off to explore the key outsourcee contextual internal factors and location external factors that firms consider in the search and selection stage of outsourcing manufacturing to developing countries. Our findings revealed that combining outsourcee internal factors with location external factors as two fundamental and interconnected outsourcing decisions is a complex process.

This paper, firstly, contributes through the development of a contextualisation environmental separation index as a contextualisation decision aid tool for the assessment and selection of developing country outsourcees, taking into account both internal and external environmental factors. The Environmental Separation Index assesses potential outsourcees' capabilities and alternative outsourced-to country attractiveness to achieve 
outsourcer's goals and competitive advantage from the outsourcing strategy. Secondly, by adapting a simple three-rank score (low, medium and high), the ESI is operationalised. The ESI tool not only captures the most fundamental contextual factors of outsourcees and locations but also allows for measuring and comparing their relative positions from one outsourcee to another and from one location to another. Accordingly, we extend outsourcing research which finds that outsourcing relationships are context dependent (Goffin, Lemke, and Szwejczewski 2006); and are linked to both outsourcee operational performance (internal) and location (external) contextual factors (Handley and Benton 2013, Wiengarten, Pagell, and Fynes 2013, Huq, Stevenson, and Zorzini 2014). Thirdly, we contribute to theory expansion by adopting a complexity theory lens to explain that narrowing the contextual outsourcer-outsourcee gap facilitates a mind-set shift in outsourcing relationships from hierarchies to networks and from controlling to empowering.

Current research on supplier selection explored the impact of perceived contextual and risks factors of selected supplier's capabilities and performance on the outsourcing firm performance (Lockamy and McCormack 2010, Koufteros, Vickery, and Dorge 2012, Kenyon, Meixell, and Westfall 2016, Dupont et al. 2018, Ishizaka and Lopez 2018). For example, it was reported that potential outsourcee's lack of human resources management capabilities, mismatch in organizational culture and poor level of IT integration can be of detrimental effect on the future of the outsourcing relationship (Pawar and Rogers 2013, Plugge and Bouwman 2013, Handley and Angst 2015, Schoenherr, Narayanan, and Narasimhan 2015). Our study supports and extends this line of research, by identifying and validating six key outsourcee contextual internal factors and operationalising them. Our proposed internal ESI tool examines the deviations in outsourcee perceived capabilities from outsourcer's targets 
of cost savings, quality and reliability performance and the differences in its human resources, organisational culture and processes from those of the outsourcer. The internal ESI ranks the severity of these deviations and differences and predicts their impact on the future of outsourcing performance and the evolution prospects of the outsourcing relationship.

We also construct four key location-related (external) contextual factors government policy, national human resources, infrastructure and transport and national cultural - and operationalise it. Our findings are concurrent with the limited number of studies which explored partially the outsourced-to country contextual factors and concluded that several uncertainties of outsourcing relationships can be assigned to one or more of these factors and hence can cast a major shadow on the future of the outsourcing relationship (Tjader, Shang, and Vargas 2010, Handley and Benton 2013, Wiengarten, Pagell, and Fynes 2013, Handley and Angst 2015, Huq, Pawar, and Rogers 2016, Kaur, Singh, and Majumdar 2018). For example, our case study research shows that the strength of outsourced-to country's legal system is very crucial for the flow of knowledge between outsourcing partners. In addition, the availability and status of roads, rails, ports and energy infrastructure is equally crucial to the smoothness of product flow. Moreover, we find that these factors are not mutually exclusive or independent. For example, government policy is highly interconnected with national human resources issues, since the availability of highly educated and talented human resources in a country is normally correlated with the availability and strength of public universities and technical training institutions (Kedia and Mukherjee 2009).

Finally, by establishing the outsourcing relationships as a complex adaptive system, we highlight that narrowing of the contextual outsourcer-outsourcee gap can lead to an attitudinal alteration i.e. transformation of outsourcing relationships from hierarchies to 
networks and from controlling to empowering. More specifically, outsourcing relationships should strike a balance between control (allocating tasks and evaluating performance) and emergence (empowerment of supply chain actors). Accordingly, developed country outsourcers can maximise the utilisation and predictability of the ESI tool by constantly responding and adapting to the complexity in their outsourcee internal and external contexts. Moreover, they can expand the use of the ESI tool for (re)evaluating the scope of their outsourcing relationships. For instance, by narrowing the outsourcer-outsourcee separation gap, the relationship can evolve to a more collaborative form; whereas if the gap widens, it can lead to stagnation or termination of the relationship and thus derail the execution of the outsourcing strategy.

\subsection{Managerial Implications, Limitations and Future Research}

To deal with fast-changing pace of current business environments is a primary challenge for developing country outsourcers and also an opportunity to destroy old paradigms of traditional tightly controlled outsourcing relationships. The practices and formal controlling policies of a "master-servant" outsourcing relationship are necessary, but insufficient. Thus, outsourcers should be searching for unorthodox solutions as high relationship complexity need not be managed by an ever expanding rulebook and standard processes. In order to adapt to today's competitive markets, early adopters of a post-hierarchical "peer to peer" outsourcing relationships are more likely to succeed. The bottom line is that managing hierarchical outsourcing relationships is no longer suited for the challenges of the modern economy. Every pillar of a traditional supply network is now in a flux. Outsourcers cannot afford to discount contextual awareness and therefore, need to build relationships that can change as fast as change itself. 
Although, the identified contextual internal and external factors within our ESI tool are adequately qualified through outsourcing literature and then verified in findings from this research, these factors are not claimed to be comprehensive, but instead represent some of the more prominent issues in offshore outsourcing relationships. Even though we adopted an intuitive and rigorous methodology to measure the ESI, which accomplishes the goal of presenting managers with an easy to measure yet informative outsourcee and location evaluation tool, the ESI will benefit from further validation in future research. Since we conducted our study from the perspective of European outsourcers, it would be interesting to explore how developing country outsourcees take into account internal and external contextual factors of their developed country partners and how they rank them in terms of importance in order to better understand the developing country outsourcee perspective, which is currently missing.

Finally, an avenue of future research can be to study extreme cases of the outsourceroutsourcee relationship reversing 360 degrees i.e. the conditions under which the 'servant' becomes the 'master'. This might happen gradually, but we envisage that the conditions are ripe with India and China growing at a much faster rate than the developed world and moving up higher in the manufacturing value chain. For example, an extraordinary \$234 billion of overseas purchases was announced by Chinese companies in 2016 (Bloomberg 2016). The relatively recent sale of Jaguar and Land Rover to India-based Tata Motors by Ford Motor and Chinese computer maker Lenovo's purchase of IBM's personal computer division are precursors to this phenomenon. Thus, it would be valuable to investigate how narrowing of internal and external contextual environmental factors can lead to a 'servant' becoming the 'master'. 


\section{Acknowledgements}

The authors wish to acknowledge that this research was carried out as part of the UK-INDIA Science Bridge BIOPHARM 2020 project funded by DST, India and Research Council UK. We also wish to acknowledge our gratitude and appreciation to all those who contributed to the developments of ideas and concepts presented in this paper.

Aamer, A.M. 2018. "Outsourcing in non-developed supplier markets: a lean thinking approach." international Journal of Production Research in press. doi: 10.1080/00207543.2018.1465609.

Arampantzi, ., I. Minis, and G. Dikas. 2018. "A strategic model for exact supply chain network design and its application to a global manufacturer." International Journal of Production Research. doi: 10.1080/00207543.2018.1489155.

Bals, L., J. F. Kirchoff, and K. Foerstl. 2016. "Exploring the reshoring and insourcing decision making process: toward an agenda for future research." Operations Management Research 9 (34):102-116. doi: 10.1007/s12063-016-0113-0.

Beaumont, N., and A. Sohal. 2004. "Outsourcing in Australia." International Journal of Operations and Prodcution Management 24 (7):688-700.

Bloomberg. 2016. "Ten Surprising Things China Is Buying This Year." accessed Accessed on 23rd December, 2017. https://www.bloomberg.com/news/articles/2016-11-30/ten-surprisingthings-china-is-buying-this-year.

Brahm, F., and J. Tarzijan. 2016. "Relational Contracts and Collaboration in the Supply Chain: Impact of Expected Future Business Volume on the Make-Or-Buy Decision." Journal of Supply Chain Management 52 (3):48-67. doi: 10.1111/jscm.12110.

Buttol, P., R. Buonamici, L. Naldesi, C. Rinaldi, A. Zamagni, and P. Masoni. 2012. "Integrating services and tools in an ICT platform to support eco-innovation in SMEs." Clean Technologies and Environmental Policy 14 (2):211-221. doi: 10.1007/s10098-011-0388-7.

Caniato, F., S. Elia, D. Luzzini, L. Piscitello, and S. Ronchi. 2015. "Location drivers, governance model and performance in service offshoring." International Journal of Production Economics 163:189-199. doi: 10.1016/j.ijpe.2014.09.011.

Carter, R.C., D.S. Rogers, and T.Y. Choi. 2015. "Toward the theory of the supply chain." Journal of Supply Chain Management 51 (2):89-97.

Che, Z.H., and T.A. Chiang. 2012. "Designing a collaborative supply-chain plan using the analytic hierarchy process and genetic algorithm with cycle-time estimation." International Journal of Production Research 50 (16):4426-4443.

Chen, K. S., and K.L. Chen. 2006. "Supplier selection by testing the process incapability index." International Journal of Production Research 44 (3):589-600.

Chen, L. H., and C. C. Hung. 2010. "An integrated fuzzy approach for the selection of outsourcing manufacturing partners in pharmaceutical R \& D." International Journal of Production Research 48 (24):7483-7506. doi: 10.1080/00207540903365308.

Choi, T.Y., K.J. Dooley, and M. Rungtusanatham. 2001. "Supply networks and complex adaptive systems: control versus emergence." Journal of Operations Management 19 (3):351-366.

Day, J.M. 2014. "Fostering emergent resilience: the complex adaptive supply network of disaster relief." International Journal of Production Research 52 (7):1970-1988.

Dekkers, R. 2011. "Impact of strategic decision making for outsourcing on managing manufacturing." International Journal of Operations \& Production Management 30 (9):935-965. doi: 10.1108/01443571111165839.

Dolgui, A., and J. M. Proth. 2013. "Outsourcing: definitions and analysis." International Journal of Production Research 51 (23-24):6769-6777. doi: 10.1080/00207543.2013.855338. 
Dupont, L. , C. Bernard, F. Hamdi, and F. Masmoudi. 2018. "Supplier selection under risk of delivery failure: a decision-support model considering managers' risk sensitivity." international Journal of Production Research 56 (3):1054-1069.

Dyer, J.H., and H. Singh. 1998. "The relational view: Cooperative strategy and sources of the interorganizational competitive advantage." Academy of Management Review 23 (4):660697.

Eisenhardt, Kathleen M, Melissa E Graebner, and Scott Sonenshein. 2016. "Grand challenges and inductive methods: Rigor without rigor mortis." Academy of Management Journal 59 (4):1113-1123.

Eisenhardt, Kathleen M. 1989. "Building Theories from Case Study Research." Academy of Management Review 14 (4):532-550.

Emrouznejad, Ali, and Marianna Marra. 2017. "The state of the art development of AHP (19792017): A literature review with a social network analysis." International Journal of Production Research 55 (22):6653-6675.

European Commission. 2016. "Countries and regions." accessed 22nd December, 2017. http://ec.europa.eu/trade/policy/countries-and-regions/countries/india/index en.htm.

Eurostat. 2016. "Eurostart yearbook " In. Luxembourg (LU): European Union. http://ec.europa.eu/eurostat/statistics-explained/index.php?title=IndiaEU \%E2\%80\%93 international trade in goods statistics\&oldid=355530\#EU and India in world trade in goodsS (accessed 04-12-2017).

Flynn, B.B., B. Hou, and X. Zhao. 2010. "The impact of supply chain integration on performance: A contingency and configuration approach." Journal of Operations Management 28 (1):58-71.

Foa, R., and J.C. Tanner. 2012. "Methodology of the indicies of social development (No. 2012-04)." ISD - Working Paper Series.

Freel, M., and P. J. Robson. 2017. "Appropriation strategies and open innovation in SMEs." International Small Business Journal-Researching Entrepreneurship 35 (5):578-596. doi: $10.1177 / 0266242616654957$.

Goffin, K., F. Lemke, and M. Szwejczewski. 2006. "An exploratory study of 'close' suppliermanufacturer relationships." Journal of Operations Management 24:189-209.

Gulati, R., and M. Sytch. 2008. "Does familiarity breed trust? Revisiting the antecedents of trust." Managerial and Decision Economics 29 (2-3):165-190.

Handley, S. M., and C. M. Angst. 2015. "The impact of culture on the relationship between governance and opportunism in outsourcing relationships." Strategic Management Journal 36 (9):1412-1434. doi: 10.1002/smj.2300.

Handley, S. M., and W. C. Benton. 2013. "The influence of task- and location-specific complexity on the control and coordination costs in global outsourcing relationships." Journal of Operations Management 31 (3):109-128. doi: 10.1016/j.jom.2012.12.003.

Hansen, C., C. Mena, and H. Skipworth. 2017. "Exploring political risk in offshoring engagements." International Journal of Production Research 55:7 (7):2051-2067.

Hatonen, J., and T. Eriksson. 2009. "30+ years of research and practice of outsourcing: Exploring the past and anticipating the future." Journal of International Management 15 (2):142-155.

Hofstede, G. . 1980. Culture's Consequences, International Differences in Work-Related Values. Beverly Hills, CA.: Sage.

Hofstede, G., and M. Minkov. 2010. "Long- versus short-term orientation: new perspectives." Asia Pacific Business Review 16 (4):493-504. doi: 10.1080/13602381003637609.

Huq, F., K. Pawar, and H. Rogers. 2016. "Supply chain configuration conundrum: how does the pharmaceutical industry mitigate disturbance factors?" Production Planning \& Control 27 (14):1206-1220. doi: 10.1080/09537287.2016.1193911.

Huq, Fahian Anisul, and Mark Stevenson. 2018. "Implementing Socially Sustainable Practices in Challenging Institutional Contexts: Building Theory from Seven Developing Country Supplier Cases." Journal of Business Ethics. doi: 10.1007/s10551-018-3951-x. 
Huq, Fahian Anisul, Mark Stevenson, and Marta Zorzini. 2014. "Social sustainability in developing country suppliers: An exploratory study in the ready made garments industry of Bangladesh." International Journal of Operations \& Production Management 34 (5):610-638.

International Labour Organization. 2017. "Labour Prodcutivity." International Labour Organization, accessed 22-12-2017.

http://www.ilo.org/ilostat/faces/wcnav defaultSelection;ILOSTATCOOKIE=I5B-

naw2xyrRQIAzeEDiKOng2 4aslagXmYG-GERvnVSkUgnnrqv!-482638847? adf.ctrl state $=v g 4 v 3 f$ fnge $4 \&$ afrLoop $=86215761992392 \&$ afrWindowMode $=0 \&$ afrWindowld $=$ null \#!\%40\%40\%3F afrWindowld\%3Dnull\%26 afrLoop\%3D86215761992392\%26 afrWindowMo de\%3D0\%26 adf.ctrl-state\%3D10crhbwjx7 4.

Ishizaka, A., and A. Labib. 2011. "Selection of new production facilities with the Group Analytic Hierarchy Process Ordering method." Expert Systems with Applications 38 (6):7317-7325.

Ishizaka, A., and C. Lopez. 2018. "Cost-Benefit AHPSort for performance analysis of offshore providers." international Journal of Production Research in press. doi: 10.1080/00207543.2018.1509393.

Jayasuriya, D. 2011. "Improvements in the World Bank's Ease of Doing Business Rankings Do they Translate into Greater Foreign Direct Investment Inflows?" In. Sydney: The World Bank. https://papers.ssrn.com/sol3/papers.cfm?abstract id=1923545 (accessed Direct Investment Inflows?).

Jensen, P.D.., and T. Pedersen. 2011. "The economic geography of offshoring: The fit between activities and local context." Journal of Management Studies 48:2 March 201148 (1):352372.

Kaur, H., S.P. Singh, and A. Majumdar. 2018. "Modelling joint outsourcing and offshoring decisions." International Journal of Production Research in press. doi: 10.1080/00207543.2018.1471245.

Kedia, B.L., and D. Mukherjee. 2009. "Understanding offshoring: A research framework based on disintegration, location and externalization advantages." Journal of World Business 44 (3):250-261.

Kenyon, G. N., M. J. Meixell, and P. H. Westfall. 2016. "Production outsourcing and operational performance: An empirical study using secondary data." International Journal of Production Economics 171:336-349. doi: 10.1016/j.ijpe.2015.09.017.

Khramov, V., and J Lee Ridings. 2013. The Economic Performance Index (EPI): an Intuitive Indicator for Assessing a Country's Economic Performance Dynamics in an Historical Perspective Washington DC: International Monetary Fund

Koufteros, X., S.K. Vickery, and C. Dorge. 2012. "The Effects of strategic supplier selection on buyer competitive performance in matched domains: Does supplier integration mediate the relationships?" Journal of Supply Chain Management 48 (2):83-115. doi: 10.1111/j.1745493X.2012.03263.x.

Lahiri, S., and B.L. Kedia. 2011. "Co-evolution of institutional and organizational factors in explaining offshore outsourcing." International Business Review 20 (3):252-63.

Leng, J. W., P. Y. Jiang, and K. Ding. 2014. "Implementing of a three-phase integrated decision support model for parts machining outsourcing." International Journal of Production Research 52 (12):3614-3636. doi: 10.1080/00207543.2013.879344.

Lewin, A.Y., S. Massani, and C. Peeters. 2009. "Why are companies offshore outsourcing innovation? The emerging global race for talent." Journal of International Business Studies 40 (6):901925. doi: 10.1057/jibs.2008.92.

Liker, Jeffrey K, and Thomas Y Choi. 2004. "Building deep supplier relationships." Harvard Business Review 82 (12):104-113.

Lincoln, Y.S., and E.G. Guba. 1985. Naturalistic enquiry. Newbury Park: Sage.

Lockamy, A., and K. McCormack. 2010. "Analysing risks in supply networks to facilitate outsourcing decisions." International Journal of Production Research 48 (2):593-611. doi: 10.1080/00207540903175152. 
Manson, S.M. 2001. "Simplifying complexity: A review of complexity theory." Geoforum 32 (1):405414.

Medhi, P. K., and S. Mondal. 2016. "A neural feature extraction model for classification of firms and prediction of outsourcing success: advantage of using relational sources of information for new suppliers." International Journal of Production Research 54 (20):6071-6081. doi: 10.1080/00207543.2016.1174342.

Miles, M.B., and A.M. Huberman. 1994. Qualitative data analysis, an expanded sourcebook, Thousand Oaks, . CA: Thousands Oaks, Sage.

OECD. 2016. " Education attainment - Population with tertiary education - OECD Dat." OECD, accessed 22nd December, 2017. https://data.oecd.org/eduatt/population-with-tertiaryeducation.htm.

Ordoobadi, S.M. 2009. "Development of a supplier selection odel using fuzzy logic." Supply Chain Management-an International Journal 14 (4):314-327.

Pathak, S.D. , J.M. Day, A. Nair, W.J Sawaya, and M.M. Kristal. 2007. "Complexity and adaptivity in supply networks: Building supply network theory using a complex adaptive systems perspective." Decision Sciences 38 (4):547-780.

Paulraj, A., A.A. Lado, and I.J. Chen. 2008. "Inter-organizational communication as a relational competency: Antecedents and performance outcomes in collaborative buyer-supplier relationships." Journal of Operations Management 26 (1):45-64.

Pawar, K., and H. Rogers. 2013. "Contextualising the holistic cost of uncertainty in outsourcing manufacturing supply chains." Production Planning \& Control 24 (7):607-620. doi: 10.1080/09537287.2012.659872.

Plugge, A., M. Borman, and M. Janssen. 2016. "Strategic manoeuvers in outsourcing arrangements The need for adapting capability in delivering long-term results." Strategic Outsourcing-an International Journal 9 (2):139-158. doi: 10.1108/so-12-2015-0031.

Plugge, A., and H. Bouwman. 2013. "Fit between sourcing capabilities and organisational structure on IT outsourcing performance." Production Planning \& Control 24 (4-5):375-387. doi: 10.1080/09537287.2011.648489.

Ridder, Hans-Gerd, Christina Hoon, and Alina McCandless Baluch. 2014. "Entering a dialogue: Positioning case study findings towards theory." British Journal of Management 25 (2):373387.

Robinson, O.C. . 2014. "Sampling in Interview-Based Qualitative Research: A Theoretical and Practical Guide." Qualitative Research in Psychology 11 (1):25-41. doi: 10.1080/14780887.2013.801543.

Saunders, M., P. Lewis, and A. Thornhill. 2009. Research methods for business students. Harlow, UK: Pearson Education.

Scherrer-Rathje, M., P. Deflorin, and G. Anand. 2014. "Manufacturing flexibility through outsourcing: effects of contingencies." International Journal of Operations \& Production Management 34 (9):1210-1242. doi: 10.1108/ijopm-01-2012-0033.

Schoenherr, T. 2010. "Outsourcing decisions in global supply chains: an exploratory multi-country survey." International Journal of Production Research 48 (2):343-378.

Schoenherr, T., S. Narayanan, and R. Narasimhan. 2015. "Trust formation in outsourcing relationships: A social exchange theoretic perspective." International Journal of Production Economics 169:401-412. doi: 10.1016/j.ijpe.2015.08.026.

Sehl, K. . 2018. "Build It and They Will Cluster: Meet the World's Leading Aerospace Hubs." APEX. Accessed 26th June 2018.

Selko, A. 2012. "Rolls-Royce Sets Up Supply Chain Office in Mexico." IndustryWeek. Accessed 26th June, 2018.

Sucky, E. . 2007. "A model for dynamic strategic vender selction." Computers and Operations Research 34 (12):3638-3651. doi: 10.1016/j.cor.2006.01.006. 
Tan, K.H. 2007. "A framework of supply chain management literature." European Journal of Purchasing and Supply Management 7 (1):38-48.

Tjader, Y. C., J. S. Shang, and L. G. Vargas. 2010. "Offshore outsourcing decision making: A policymaker's perspective." European Journal of Operational Research 207 (1):434-444. doi: 10.1016/j.ejor.2010.03.042.

Transparency International. 2016. "Corruption Perceptions Index 2016." accessed 22-12-2017. https://www.transparency.org/news/feature/corruption perceptions index 2016?gclid=CjO KCQiA9 LRBRDZARIsAACLXjfCrO4 xaO8 qu-Di7VMwgYKwOjVPW70Q mQ8NsuRVdQgcIXfn7RlaAhTwEALw wcB\#table.

Uluskan, M., J. A. Joines, and A. B. Godfrey. 2016. "Comprehensive insight into supplier quality and the impact of quality strategies of suppliers on outsourcing decisions." Supply Chain Management-an International Journal 21 (1):92-102. doi: 10.1108/scm-04-2015-0140.

Wadhwa, V.A., and R. Ravindran. 2007. "Vendor selection in outsourcing." Computer and Operations Research 34 (1):3725-3737.

Westphal, P., and A. S. Sohal. 2013. "Taxonomy of outsourcing decision models." Production Planning \& Control 24 (4-5):347-358. doi: 10.1080/09537287.2011.648486.

Wiengarten, F., M. Pagell, and B. Fynes. 2013. "The importance of contextual factors in the success of outsourcing contracts in the supply chain environment: the role of risk and complementary practices." Supply Chain Management-an International Journal 18 (6):630643. doi: 10.1108/scm-03-2013-0071.

World Bank. 2015. "Worldwide Governance Indicators | DataBank." The World Bank Group, Last Modified 23rd December, 2017, accessed 22rd December, 2017. http://databank.worldbank.org/data/reports.aspx?Report Name=World-Bank-Data-Rule-ofLaw\&ld=c92bd494.

World Bank. 2016. Measuring Rural Access Using new technologies. Washington, DC: The World Bank Group.

World Bank. 2017. "Enterprise Surveys | DataBank." The World Bank Group, accessed 22nd December, 2017. http://databank.worldbank.org/data/reports.aspx?source=enterprisesurveys\#.

Yang, Q., X. D. Zhao, H. Y. J. Yeung, and Y. P. Liu. 2016. "Improving logistics outsourcing performance through transactional and relational mechanisms under transaction uncertainties: Evidence from China." International Journal of Production Economics 175:12-23. doi: 10.1016/j.ijpe.2016.01.022.

Yin, RK. 2009. Case study research: Design and methods. 4th ed. Vol. 5. Thousand Oaks: Sage.

Zorzini, Marta, Linda C. Hendry, Fahian Anisul Huq, and Mark Stevenson. 2015. "Socially responsible sourcing: reviewing the literature and its use of theory." International Journal of Operations \& Production Management 35 (1):60-109. doi: doi:10.1108/IJOPM-07-2013-0355. 